\title{
PREVALENCE OF CURRENT TOBACCO USE AMONG SECONDARY STUDENTS IN NEPAL: A META-ANALYSIS
}

\author{
RR Dhungana ${ }^{1 *}$, MK Khanal ${ }^{2}$, A Baniya ${ }^{3}$ \\ ${ }^{1}$ Bangladesh Institute of Health Sciences, Dhaka University, Dhaka, Bangladesh. \\ ${ }^{2}$ Bangladesh Institute of Health Sciences, Dhaka University, Dhaka, Bangladesh. \\ ${ }^{3}$ Department of Nursing, Chitwan Medical College, College of Nursing, Bharatpur-13, Chitwan, Nepal. \\ *Correspondence to: Dr Raja Ram Dhungana, Kathmandu, Nepal. \\ Email: raja.dhungana@gmail.com
}

\begin{abstract}
Tobacco use continues to rise among young people in middle and low income countries, causing high premature death and disability. Most importantly, its initiation starts mainly during adolescence and persists for whole life. We conducted this meta-analysis to estimate the prevalence of current tobacco use among lower secondary to higher secondary students in Nepal. We searched and identified the studies which were published between 2003 and 2013 using MEDLINE, Google Scholar and NEPJOL. From five selected studies, total 7,832 eligible students were included in analysis. Considering the high degree of variability $(\mathrm{Q}=82.6, \mathrm{I} 2=95 \%)$ among selected studies, we used random effects model to estimate the weighted prevalence of current tobacco use and found as $13.9 \%(10.2-17.5)$. This result shows that current tobacco use among lower secondary to higher secondary students still remains high, which compels an effective implementation of tobacco control programs and policies.
\end{abstract}

Key Words: Smoking, Secondary students, Smokeless tobacco use.

\section{INTRODUCTION}

Globally more than one billion people use tobacco, comprising $80 \%$ people form low and middle income countries, and nearly a quarter of 15 years above world's population. ${ }^{1}$ Smoking or use of smokeless tobacco claims $12 \%$ of all the deaths among adults aged 30 years and over becoming the leading cause of preventable death worldwide. ${ }^{2,3}$ Of those adults aged 30-44 years who die from ischemic heart disease, $38 \%$ of the deaths are attributable to tobacco. ${ }^{3}$ It also heightens the risk of dying from lung cancer and chronic respiratory diseases. ${ }^{1}$ Smoking or use of smokeless tobacco exists in one third of Nepalese, that causes eight percent of all deaths in Nepal. ${ }^{3,4}$

Majority of people are likely to initiate smoking or start using smokeless tobacco products primarily during adolescence. ${ }^{5,6}$ Eighty eight percent of adult American smokers who smoke daily reported that they started smoking by the age of 18 years. ${ }^{5,6}$ An estimation showed that 5,500 Indian adolescents start using tobacco every day, joining the four million young people under the age of 15 who are regularly using tobacco. ${ }^{7}$ This situation is almost alike in Nepal where nearly one fifth of all 15-19 aged male are currently using any tobacco products. ${ }^{8}$

Recent downward shift (below18 years) of initiation of tobacco use is one of the major threats of tobacco epidemics. ${ }^{9}$ This changed pattern ultimately results in increased rate of tobacco use in whole population. ${ }^{10}$ More than that, early initiation of tobacco use produces various adverse health effects among young people. ${ }^{11}$ A precise estimate of rate of tobacco use among lower secondary, secondary and higher secondary students using a valid data can be utilized to depict the changes in trends. It also helps to reduce the discrepancies among available study findings. Therefore, we aimed to extract available and published data, and estimate the prevalence of current tobacco use among lower secondary, secondary and higher secondary school in Nepal.

\section{METHOD}

\section{Literature searches}

We searched all primary epidemiological studies on prevalence of current tobacco use among lower secondary, secondary and higher secondary Nepalese students conducted between 2003 and 2013, using three electronic databases: MEDLINE, Google Scholar and NEPJOL. We used the keywords "Smoking OR Tobacco Consumption AND Prevalence AND Nepal" for searching and identifying the articles. Results were also supplemented by useful references cited in key articles.

\section{STUDY SELECTION AND EVALUATION}

After a quick screening of title, we eliminated 15 papers that were duplicated and 76 papers that were clearly not relevant to meta-analysis. In second step, the remaining papers were assessed individually by two authors of this study. Twenty two articles did not meet the inclusion criteria of: population based cross-sectional study, lower secondary, secondary and 
higher secondary student as study unit, and study duration between 2003 and 2013. ${ }^{1}$ Two articles were removed after the qualitative evaluation as the study populations were not the representative of general population. ${ }^{12,13}$ Finally, five papers were included in the meta-analysis. ${ }^{14,15,16,17,18}$

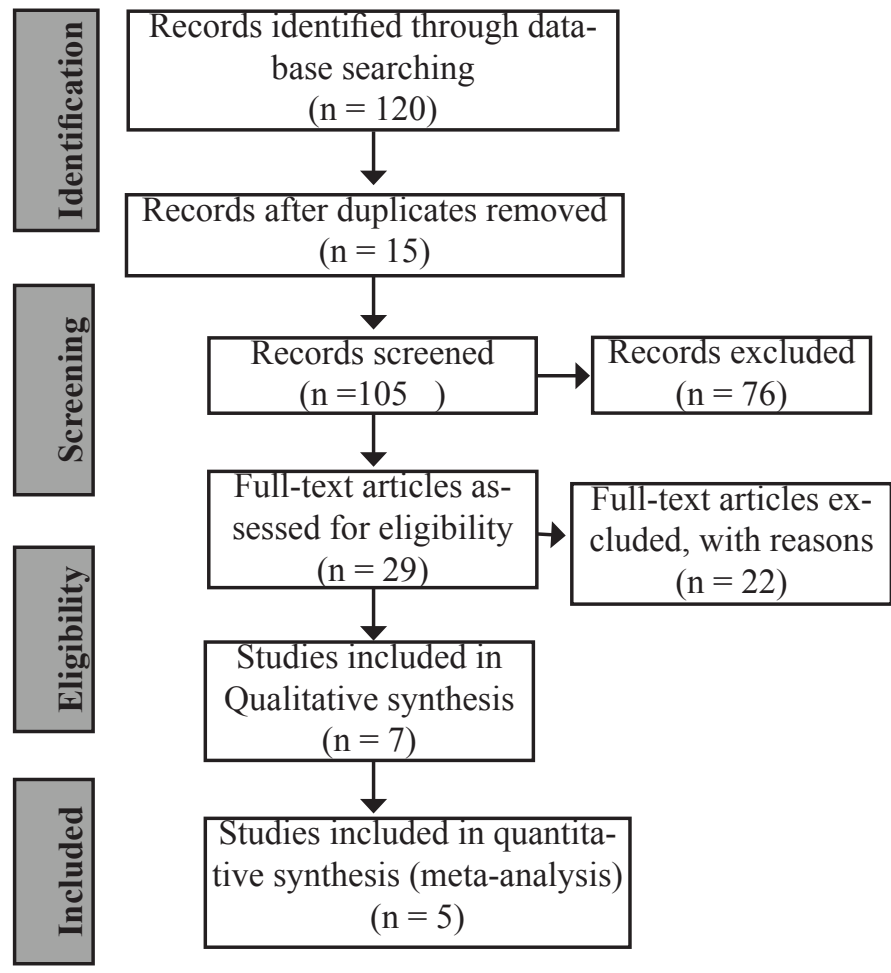

Figure 1- Study selection flow diagram

\section{Data extraction}

First, the definition of "current tobacco use" was adopted from Centers for Disease Control and Prevention (CDC), U.S. Department of Health and Human Services to ensure its uniformity among studies. The current tobacco use was defined as the smoking or use of smokeless tobacco products on at least one day during the past 30 days. ${ }^{19}$ Then, Data collection form was used to extract information about "place of study, study design, study group, sample size and reported prevalence rate."

\section{Study}

CI $(95 \%)$

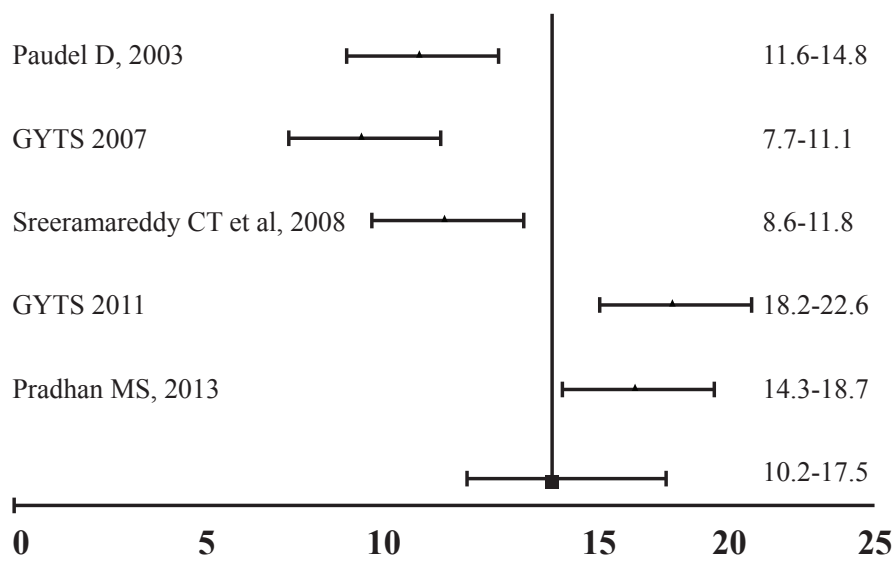

Figure 2: Comparison of estimated result with prevalence of selected studies

\section{Data analysis}

Extracted summary statistics were analyzed using Microsoft Office Excel 2007. We followed the detailed steps of metaanalysis as explained in article "Meta-analyses and Forest plots using a Microsoft excel spreadsheet: step-by-step guide focusing on descriptive data analysis." ${ }^{20}$ Standard error for prevalence of tobacco use in each study was calculated based on the binary distribution formula. The weights of studies were calculated taking inverse of the variance. The test of heterogeneity $(\mathrm{Q}$ statistic or Hedge's Q test) was conducted taking the ratio of the (squared) deviations between the effect sizes to the (squared) expected deviation. The significance level for this statistic was set as 0.05 . Based on the results of the heterogeneity test, random effects model $(\mathrm{P}<0.05)$ was used to estimate the weighted mean effect size and standard error of mean effect size of the studies. Forest plot was designed using same version of excel and later it is added with each article IDs using Adobe Photoshop version 8.0.

\section{RESULT}

We located five studies that met the inclusion criteria. A total of 7,832 lower secondary, secondary and higher secondary students were eligible and included in analysis (Table 1). Among five selected studies, two studies belonged to Global Youth Tobacco Survey. The lowest and highest primary research rates were 5 and 20.

Table 1: Characteristics of studies included in meta-analysis

\begin{tabular}{|l|l|l|l|l|l|l|l|}
\hline SN & Article ID & Place of Study & Study design & Study group & Sample size & Prevalence & Time of Study \\
\hline 1 & Paudel D, 2003 & Pokhara & Cross sectional & $\begin{array}{l}\text { Secondary School } \\
\text { Students }\end{array}$ & 2032 & $13.2 \%$ & 2003 \\
\hline 2 & $\begin{array}{l}\text { Pradhan PMS } \\
\text { et al, 2013 }\end{array}$ & Dharan & Cross sectional & $\begin{array}{l}\text { Secondary and } \\
\text { Higher Secondary } \\
\text { School students }\end{array}$ & 1312 & $16.46 \%$ & 2013 \\
\hline 3 & $\begin{array}{l}\text { Sreeramareddy } \\
\text { CT et al, 2008 }\end{array}$ & Pokhara & Cross sectional & $\begin{array}{l}\text { Higher Secondary } \\
\text { students }\end{array}$ & 1590 & $10.2 \%$ & 2007 \\
\hline
\end{tabular}


Dhungana et al, Journal of Chitwan Medical College 2013; 3(6)

\begin{tabular}{|l|l|l|l|l|l|l|l|}
\hline 4 & GYTS, 2007 & Nationwide & Cross sectional & $\begin{array}{l}\text { Lower secondary } \\
\text { and Secondary } \\
\text { School students }\end{array}$ & 1296 & $9.4 \%$ & 2007 \\
\hline 5 & GYTS, 2011 & Nationwide & Cross sectional & $\begin{array}{l}\text { Lower Secondary } \\
\text { and Secondary } \\
\text { School students }\end{array}$ & 1602 & $20.4 \%$ & 2011 \\
\hline
\end{tabular}

In test of heterogeneity, Q value exceeded the critical Chi-square value showing significant between-studies variability given the four degree of freedom and five percent level of statistical significance. The percentage of variability (I2) among the effect sizes existed between the studies relative to the total variability of effect sizes was $95 \%$. After adjusting the weight of the study with a between-studies variance component v (0.001657) in random effects model, Q $(\chi 2=4.7)$ was found to be statistically insignificant (Table 2).

Table 2: Summary calculation of prevalence of current tobacco use among lower secondary, secondary and higher secondary Nepalese students

\begin{tabular}{|c|c|c|c|c|c|c|c|c|c|c|c|c|}
\hline Study ID & $\begin{array}{l}\text { Sample } \\
\text { size }\end{array}$ & es & SE & Var & W & $\mathrm{W}^{*} \mathrm{es}$ & $\mathrm{w} * \mathrm{es} 2$ & w2 & Wv & Wv*es & $\mathrm{Wv} *(\mathrm{es}) 2$ & Wv2 \\
\hline Paudel D,2003 & 2032 & 0.132 & 0.00806 & $6.49606 \mathrm{E}-05$ & 15393.94 & 2032 & 268.224 & 236973370 & 580.6841 & 76.65031 & 10.11784 & 337194.1 \\
\hline $\begin{array}{l}\text { Pradhan MS, } \\
2013\end{array}$ & 1312 & 0.1646 & 0.011201 & 0.000125457 & 7970.838 & 1312 & 215.9552 & 63534264.7 & 560.9773 & 92.33687 & 15.19865 & 314695.5 \\
\hline $\begin{array}{l}\text { Sreeramareddy } \\
\text { CT et al, } 2008\end{array}$ & 1590 & 0.102 & 0.008009 & $6.41509 \mathrm{E}-05$ & 15588.24 & 1590 & 162.18 & 242993080 & 580.9573 & 59.25764 & 6.04428 & 337511.4 \\
\hline GYTS 2007 & 1296 & 0.094 & 0.008517 & $7.25309 \mathrm{E}-05$ & 13787.23 & 1296 & 121.824 & 190087823 & 578.1427 & 54.34541 & 5.108469 & 334249 \\
\hline GYTS 2011 & 1602 & 0.204 & 0.011285 & 0.000127341 & 7852.941 & 1602 & 326.808 & 61668685.1 & 560.3852 & 114.3186 & 23.32099 & 314031.6 \\
\hline & & & & Sums & 60593.19 & 7832 & 1094.991 & 795257222 & 2861.147 & 396.9088 & 59.79023 & 1637682 \\
\hline $\begin{array}{l}K=5 \\
D f=4\end{array}$ & \multicolumn{12}{|c|}{$\mathrm{V}=0.001657$} \\
\hline $\begin{array}{l}\mathrm{Q}=82.66249 \\
\mathrm{I} 2=95.16105 \\
\text { es(fixed) }= \\
0.129255\end{array}$ & $\begin{array}{l}\mathrm{Qv}=4.7 \\
\mathrm{I} 2 \mathrm{v}=15 \\
\text { es (rando } \\
\text { SEes (ra } \\
\mathrm{CI}=0.1\end{array}$ & $\begin{array}{l}574157 \\
2578957 \\
=0.139 \\
\text { om })=0.0 \\
08111,0.1\end{array}$ & $\begin{array}{l}18695192 \\
75366\end{array}$ & & & & & & & & & \\
\hline
\end{tabular}

The weighted mean effect size was calculated in random effects model and was found to be 0.139 with standard error of 0.0187 , which gave the weighted prevalence of the studies as $13.9 \%(\mathrm{CI}=10.2-17.5)$

\section{DISCUSSION}

We conducted this study to estimate the overall prevalence of current tobacco use among lower secondary, secondary and higher secondary Nepalese students. The weighted prevalence was $13.9 \%(\mathrm{CI}=10.2-17.5)$. This rate is two times higher than the prevalence of currently reported any tobacco use among 14 to 19 adolescents in NDHS $2006(7.7 \%) .{ }^{21}$ It is also well comparable with the prevalence of any current tobacco use among Indian (14.6\%) and Bangladeshi (6.9\%) adolescents students. ${ }^{22}$

After a review of five studies, we found a noticeable incongruity among the given prevalence rates. The GYTS 2011 rate $(20.4 \%)$ was two times higher than GYTS 2009 rate (9.4\%). ${ }^{14,15,17}$ The percentage of any tobacco use in same group was just 7.8 in $2001 .^{23}$ This contrasts with linear decline in current cigarette smoking among middle school and high school American youth between 2000 and 2011. ${ }^{19}$ But, the findings substantiate the fact that tobacco use is on the rise among youth in low and middle income countries. ${ }^{24,25}$

According to $\mathrm{WHO}$, in recent years, tobacco industries have shifted the target towards low and middle income countries (LMCs) in order to increase sales and profits because of reduction in number of cigarette smokers in developed nations. ${ }^{25}$ Apart from this, increase in cigarettes sale among LMCs is also associated with recent exploding of young population, weak implementation of tobacco control policies and lower levels of health awareness. ${ }^{26}$ Some studies have also suggested that social 
norms portrayed in tobacco advertising, smoking scenes used in movies and peer pressure are some reasons behind high proportion of tobacco use among youth. ${ }^{5,6}$

This study has limitations. Only five studies were eligible and included in analysis. Among them, only two studies could represent whole population. We could not consider separate analysis of sex, age and grade levels because of insufficient studies.

\section{CONCLUSION}

This meta-analysis provides the evidence of high variability among available study findings. After meta-analysis, the precise estimate remains to be $13.9 \%$, which demonstrates the increasing trend of tobacco use among study groups, necessitating the effective endorsement of national and international efforts to protect them from its deleterious effects.

\section{REFERENCES}

1. World Health Organization. Global Status Report on Non-communicable Diseases 2010. Italy: World Health Organization. 2010. http://whqlibdoc.who.int/ publications/2011/9789240686458_eng.pdf. Accessed July 20, 2013.

2. World Health Organization. WHO REPORT ON THE GLOBAL TOBACCO EPIDEMIC, 2011: Warning about the dangers of tobacco. Italy: World Health Organization. 2011. http://whqlibdoc.who.int/ publications/2011/9789240687813_eng.pdf. Accessed July 27, 2013.

3. World Health Organization. WHO Global Report: Mortality Attributable to Tobacco: World Health Organization. 2012. http://whqlibdoc.who.int/ publications/2012/9789241564434_eng.pdf. Accessed August 20, 2013.

4. World Health Organization. Risk factors: Tobacco by country. World Health Organization. 2013. http://apps. who.int/gho/data/node.main.65. Accessed October 10, 2013.

5. U.S. Department of Health and Human Services. Preventing Tobacco Use Among Young People: A Report of the Surgeon General. Atlanta: U.S. Department of Health and Human Services, Centers for Disease Control and Prevention, Office on Smoking and Health. 1994. http://profiles.nlm.nih.gov/NN/B/C/L/Q/. Accessed 2013 August 10.

6. U.S. Department of Health and Human Services. Preventing Tobacco Use Among Youth and Young Adults: A Report of the Surgeon General. Atlanta: U.S. Department of Health and Human Services, Centers for Disease Control and Prevention. 2012. http://www. surgeongeneral.gov/library/reports/preventing-youthtobacco-use/full-report.pdf. Accessed August 20, 2013.

7. Sinha DN, Gupta PC, Pednekar M. Tobacco use among students in Bihar (India). Indian J Public Health. 2004 Jul-Sep;48(3):111-7. http://www.ijph.in/temp/ IndianJPublicHealth483111-3987373_110433.pdf. Accessed August 25, 2013.

8. Ministry of Health and Population (MOHP) [Nepal], New ERA, ICF International Inc. Nepal Demographic and
Health Survey 2011. Kathmandu, Nepal: Ministry of Health and Population, New ERA, ICF International. 2012.

9. World Health Organization. WHO report on the global tobacco epidemic, 2008. Geneva, Switzerland: World Health Organization. 2008. http://www.who.int/tobacco/ mpower/mpower_report_full_2008.pdf. Accessed August $25,2013$.

10. Reddy KS, Perry CL, Stigler MH, Arora M. Differences in tobacco use among young people in urban India by sex, socioeconomic status, age, and school grade: Assessment of baseline survey data. Lancet. 2006;367:589

11. U.S. Department of Health and Human Services. Preventing Tobacco Use Among Young People: A Report of the Surgeon General. 1994

12. Aryal U, Deuba K, Subedi A, Shrestha R, Bhatta L. Prevalence and Determinants of Cigarette Smoking among the College Students of Kathmandu Valley. Asian Journal of Medical Sciences. 2011. http://www.nepjol.info/index.php/ AJMS/article/view/3279. Accessed October 1, 2013.

13. Aryal UR, Lohani SP. Perceived risk of cigarette smoking among college students. J Nepal Health Res Counc. 2011 Oct;9(2):176-80.

14. U.S. Department of Health and Human Services. Global Tobacco Surveillance System Data (GTSSData): Nepal Global Youth Tobacco Survey, 2007. U.S. Department of Health and Human Services, Centers for Disease Control and Prevention. 2013. http://nccd.cdc.gov/GTSSData/ Ancillary/DataReports.aspx?CAID=1. Accessed August $15,2013$.

15. U.S. Department of Health and Human Services. Global Tobacco Surveillance System Data (GTSSData): Nepal Global Youth Tobacco Survey, 2011. U.S. Department of Health and Human Services, Centers for Disease Control and Prevention. 2013. http://nccd.cdc.gov/GTSSData/ Ancillary/DataReports.aspx?CAID=1. Accessed August 15, 2013.

16. Paudel D, Pathak RP. Tobacco Use among Adolescent Students in Secondary Schools of Pokhara Sub Metropolitan City. J Nepal Health Res Counc. 2003 Apr;1(2).

17. Pradhan PM, Niraula SR, Ghimire A, Singh SB, Pokharel PK. Tobacco use and associated factors among adolescent students in Dharan, Eastern Nepal: a cross-sectional questionnaire survey. BMJ Open. 2013 Feb 14;3(2).

18. Sreeramareddy CT, Kishore P, Paudel J, Menezes RG. Prevalence and correlates of tobacco use amongst junior collegiates in twin cities of western Nepal: a cross-sectional, questionnaire-based survey. BMC Public Health. 2008 Mar 26;8:97.

19. U.S. Department of Health and Human Services. Current Tobacco Use Among Middle and High School StudentsUnited States, 2011: Centers for Disease Control and Prevention (CDC), U.S. Department of Health and Human Services. 2012.

20. Neyeloff JL, Fuchs SC, Moreira LB. Meta-analyses and Forest plots using a Microsoft excel spreadsheet: step-bystep guide focusing on descriptive data analysis. BMC Research Notes. 2012;5(52).

21. Sreeramareddy CT, Ramakrishnareddy N, Harsha Kumar H, Sathian B, Arokiasamy JT. Prevalence, distribution and correlates of tobacco smoking and chewing in Nepal: 
a secondary data analysis of Nepal Demographic and Health Survey-2006. Subst Abuse Treat Prev Policy. 2011 Dec 20;6:33.

22. World Health Organization. Risk factors: Tobacco by country. World Health Organization. 2013. http://apps. who.int/gho/data/node.main.65. Accessed September 15, 2013.

23. U.S. Department of Health and Human Services. Global Tobacco Surveillance System Data (GTSSData): Nepal Global Youth Tobacco Survey, 2001. U.S. Department of Health and Human Services, Centers for Disease Control and Prevention. 2013. http://nccd.cdc.gov/GTSSData/ Ancillary/DataReports.aspx?CAID $=1$. Accessed August $15,2013$.

24. The World Bank. Curbing the epidemic: governments and the economics of tobacco control. The World Bank. Tob Control. 1999 Summer;8(3):196-201.

25. World Health Organization. Confronting the epidemic: a global agenda for tobacco control research. 1999. http:// www.who.int/tobacco/research/en/print.html. Accessed October 12, 2013.

26. Euromonitor International. Tobacco: Middle East and Africa Regional Overview. 2011. 